The impact of a disability on labour market status: A comparison of the public and private sectors

THOMAS BARNAY, EMMANUEl DUGUET, Christine Le Clainche, MATHIEU NARCY, YANN VIDEAU 
ISSN 2110-5472 


\title{
The Impact of a Disability on Labour Market Status: A Comparison of the Public and Private Sectors
}

Thomas Barnay (Université de Rouen, Créam ; ERUDITE, TEPP (FR CNRS 3435)), Emmanuel Duguet (Université Paris Est, ERUDITE, UPEC, UPEM, TEPP (FR CNRS 3435) et Centre d'Etudes de l'Emploi), Christine Le Clainche (Ens Cachan, Ces-Cachan, Cee), Mathieu Narcy (Cee ; Upec, ERUDITE, TEPP (FR

CNRS 3435)), Yann Videau (Université Paris Est, ERUDITE, UPEC, UPEM, TEPP (FR CNRS 3435)) $)^{1}$

\begin{abstract}
This study analyses the causal effect of a disability on subsequent labour market status by distinguishing between public employment and private employment in France. This study provides two original contributions. First, previous studies have not distinguished between the public and private sectors although the characteristics of these sectors are likely to affect the relationship between the occurrence of a disability and labour market status. Second, we implement a difference-in-differences approach combined with an exact and dynamic matching method, which has never been used to estimate the effect of a disability on labour market status. We utilise data from the Health and Labour Market Histories (HLMH) survey conducted in France during the period 2006-2007. The results indicate that the occurrence of a disability exerts a strong detrimental effect on private employment but has no significant effect on public employment during the five years after its occurrence. Moreover, this public/private difference is neither explained by differences in the type of disability nor by differences in the composition of the workforce employed in each sector.
\end{abstract}

JEL codes: C33, C52, I10, J20, J31

\footnotetext{
${ }^{1}$ Corresponding author : Thomas Barnay : thomas.barnay@univ-rouen.fr

We would like to thank Meriam Barhoumi-Sabraoui (Dares), Emmanuelle Cambois (Ined), Elise Coudin (Crest), Pierre-Jean Messe (Gains, Le Mans), Sébastien Roux (Banque de France), Valerie Ulrich (Drees) and the participants of TEPP Conference "Research in Health and Labour Economics", $35^{\text {th }}$ Jesf conference, Scientific workshop of $C D C$ and $63^{\text {th }}$ AFSE Congress for their helpful comments. Finally, we thank the anonymous referees for their very relevant comments.
} 


\section{Introduction}

In France, a 1987 law defines a compulsory target for the employment of persons with disabilities for public and private organisations that employee over 20 workers of at least $6 \%$ of their labour force. This obligation to employ disabled individuals (in French, obligation d'emploi des travailleurs handicaps - OETH) is coupled with a penalty to be paid by private sector firms that are non-compliant with the $6 \%$ target. A 2005 law for equal rights, opportunities, participation and citizenship for disabled individuals ensures convergence between the public and private sectors. Finally, since 2012, specific provisions for disabled persons entering or remaining in the labour market are included in every public policy. Nevertheless, these measures do not prevent large disparities in employment rates between the disabled and non-disabled populations. Indeed, in 2007, the employment rate for disabled persons of $35 \%$ for people with administrative recognition of disability is lower than that of the general population rate of $65 \%$ for people between the ages of $15-64^{2}$.

Despite the harmonisation of rules for the private and public sectors, inequalities concerning the treatment of disability remain, notably because disabled workers do not benefit from the same mechanisms of employment and professional career security. When disability occurs, those employed in the civil service benefit from specific policies (e.g., guaranteed employment, compulsory reclassification, long-term sick leave) that improve job retention compared to the private sector where people are more likely to experience a change in labour market status (shifting from employment to unemployment or nonemployment). Nonetheless, coercive measures, such as financial sanctions for companies that do not abide by the law, have also been implemented in the private sector to protect the employment of persons with disabilities. This public-private difference in the professional integration of disabled workers is supported by a number of studies. For example, Duguet AND LE CLAINCHE [2012c] note that French women who benefited from workplace accommodations after developing cancer are more likely to be employed in the public sector.

This brief overview of the variation in public and private sector employee treatment does not allows us to draw conclusions regarding the relationships among disability, functional limitations, such as physical pain at work, and labour market participation. Although some factors (e.g., a greater possibility of early retirement) imply that employees in the public sector might exit from the labour market towards non-employment early, other factors (e.g., less exposure to physical pain, greater possibility of reclassification) favour a later exit from employment.

Several economic studies analyse the relationship between disability and labour market status in various countries. However, no study considers the specificities of the public and private sectors that are likely to distort this relationship.

Therefore, we evaluate the individual effects of becoming disabled on labour market status by distinguishing between public and private sector employment. International studies on this topic can be categorized as follows: the treatment of endogeneity biases [DWyer and MitChell, 1999; Lindeboom and KeRKHOFS, 2002; Benitez-Silva et al., 2004; CAl,

\footnotetext{
${ }^{2}$ There is no difference in the employment rates of the general population and disabled persons when disabilities are broadly defined, i.e., as "persons having administrative recognition or reporting a health problem lasting over 6 months and having great difficulty traveling or having had one or several accidents over the past year" (NGUYEN AND ULRICH, 2008).
} 
2009; GANNON, 2009; AKASHI-RONQUeSt et al., 2011], the efficacy of legislative and fiscal measures related to disabilities [MItra, 2009; Staubl, 2011; Marie and Vall Castello, 2012; CAMPOLIETI AND RIDDELL, 2012] and the impact of disabilities on labour market outcomes, such as earnings, worked hours and employment.

This study belongs to the third category of studies. A first group of these studies analyse the effect of disability on labour market status utilising parametric models. Some of these studies employ cross-sectional data. For example, Jones [2011] estimates the influence of different characteristics of a disability (type, origin, duration, severity) on the probability of being employed and on labour market earnings using an ad hoc module from the 2002 UK Labour Force Survey. That study only includes people reporting disabilities and estimates the effects separately for men and women. Taking into account the selection effects of considering only employees who experience disabilities reveals that a disability is less detrimental to employment when it occurs at birth and when the disability results from a traffic accident; however, this effect is observed only for men. On the contrary, for both men and women, mental illnesses have a strong negative effect on employment.

Other studies use panel data to better account for unobserved heterogeneity affecting health shocks and labour market outcomes. For example, Lindeboom et al. [2006] identify the causal effect of the onset of a disability on employment outcomes using the National Child Development Study, which is a longitudinal study of approximately 17,000 individuals born in Great-Britain during the week of 3-9 March 1958. The authors estimate randomeffects multinomial logit models and use unanticipated health shocks (unscheduled hospitalization) as instrumental variables for the onset of disabilities. They observe that the employment rate at age 40 is reduced by approximately 21 per cent for individuals who experienced a disability at age 25 .

A second group of studies is based on similar estimation methods that resemble ours. These studies evaluate the effect of disability on labour market status using non-parametric methods that combine propensity score matching with difference-in-differences (DID) techniques. MolleR-DANO [2005] investigates the short- and long-term causal effects of a disability on disposable income, earnings, employment and public transfer income in Denmark, and the author demonstrates that 6 years after a road injury, the employment rates of the injured are 10 and 8 percentage points lower for men and women, respectively, than for non-injured persons. LECHNER AND VAZQUEZ-AlVAREZ [2011] estimate the effect of becoming disabled (officially recognised) on labour market outcomes, such as employment, unemployment, exiting the labour market, net annual earnings, per capita household disposable income, and average weekly hours worked, based on German panel data from 1984 to 2002 . Becoming disabled reduces the probability of being employed by $9 \%$ and by approximately $13 \%$ for those with a high degree of disability three years after the disability onset. Nonetheless, this reduction in the probability of being employed does not lead to an increase in the probability of being unemployed. GARCIA-GOMEZ [2011] examined the impact of a health shock, rather than strictly defined disabilities, on labour market outcomes in nine European countries utilising the European Community Household Panel. The results suggest that health shocks have a significant causal effect on the probability of employment: persons suffering from a health shock are much more likely to leave their job. Finally, in France, Duguet AND LE CLAINCHE [2012 a, b, 2014] develop a series of studies on the relationship between health shocks and labour market status. The authors consider some non-related health shocks. Contrary to previous studies, they combine exact matching (not propensity 
score matching) with a DID method. The main result is that following the occurrence of health shock, low-skilled individuals transit from employment to unemployment more frequently, while individuals with a secondary or higher level of education remain employed more often.

In this paper, we implement a DID method with exact matching to overcome a limitation of existing studies evaluating the effect of disability on labour market status. Indeed, in these studies, the group that has experienced a disability is compared to a group of individuals who have never experienced a disability during the observation period. Hence, this comparison group is constant over time and is biased because individuals who never experience a disability might possess unobserved characteristics that are likely to impact their labour market outcomes. Consequently, we adopt a treatment dynamic approach by considering a comparison group that changes over time.

The data utilised in this study are from the HLMH (Health and Labour Market Histories) ${ }^{3}$ conducted in 2006, which provides an individual/year panel specifying, for each period, individual professional and health information while controlling for individual and temporal heterogeneity. A retrospective calendar allows us to identify the exact date of disability onset, length of disability, and evolution of labour market status (including public and private sector employment) to examine how an individual's career is affected by a health shock through a rigourously constructed counterfactual.

The estimation strategy is presented in section 2. Section 3 describes the data and variables used in our analysis. In section 4, we compare the effect of a disability on public and private employment. We also conduct a sensitivity analysis to examine the robustness of our results to the type of disability and workforce composition of the public and private sectors. Finally, section 5 concludes.

\section{Estimation method}

We wish to estimate the average effect of a disability on labour market status. This estimation considers the average effect of the treatment on the treated, where a disability is a treatment. Our estimation method combines two techniques used in previous research and has four main advantages. First, we use the DID estimator (DID), which compares situations after and before the onset of a disability in the treated and not-treated groups. This method is known to eliminate some forms of correlated, unobservable heterogeneity. Second, we use a matching method to eliminate the effect of observable heterogeneity (i.e., explanatory variables). Third, in the context of DID, adding matching is equivalent to allowing for different correlated time effects in the treated and not-treated groups. Fourth, we utilise a dynamic treatment approach, that is, the comparison group (not-treated individuals) changes over time. Indeed, individuals who have not been treated at a point in time might subsequently receive the treatment ${ }^{4}$. This process overcomes the limits of existing studies evaluating the effect of disability on labour outcomes (MOLLER-DANO, 2005; Garcia-Gomez, 2011; Lechner and Vazquez-Alvarez, 2011; Duguet and Le Clainche, 2012a). In these studies, the not-treated group is composed of individuals who never experienced a

\footnotetext{
${ }^{3}$ Santé et itinéraire professionnel - SIP

${ }^{4}$ Our estimator is related to the following assumptions in the matching literature: $\mathrm{E}\left(y_{0 i t}-y_{0 i s} \mid X, \delta=1\right)=\mathrm{E}\left(y_{0 i t}-\right.$ $\left.y_{0 i s} \mid X, \delta=0\right)$ and $\mathrm{t}>\mathrm{s}$, where $y_{0}$ is the performance before (i.e., without) the treatment, $\mathrm{X}$ represents observable individual variables and $\delta$ is the treatment dummy. Individuals in the comparison group can therefore be used to evaluate the evolution treated performance.
} 
disability during the observation period. This assumption introduces selection bias that might overestimate the effect of a disability on labour market status. Indeed, individuals who never experience a disability are characterised by particularly good health, which is likely to positively impact their labour market status.

We develop the basic model as follows. First, consider the treatment group. An individual $i$ for whom we possess data for the period $\left[t_{i}^{-}, t_{i}^{+}\right]$experiences a disability in year $t_{i} \in\left[t_{i}^{-}, t_{i}^{+}\right]$. This disability influences the outcome variable denoted $y_{i t}$. The estimation problem occurs because several variables besides a disability might influence the outcome variable so that we do not observe the isolated effect of disability. For example, let $y_{i t}$ be an employment dummy, then variables (denoted $X_{i}$ ) such as education level, age, gender or lagged labour force status just before the disability might also influence current labour market status. Similarly, there might be unobservable individual variables that we expect to be constant over time. Finally, unobservable time variables representing the overall situation of the labour market also influence the outcomes of all individuals. We can model this situation as follows:

$$
y_{i, t}=f_{i}\left(X_{i}\right)+\gamma_{i} \times \delta\left(t \geq t_{i}\right)+\alpha_{i}+\beta_{0, t}+\beta_{1, t}\left(X_{i}\right)+\varepsilon_{i, t}
$$

and

$$
\delta\left(t \geq t_{i}\right)=\left\{\begin{array}{lll}
1 & \text { if } & t_{i} \leq t \leq t_{i}^{+} \\
0 & \text { if } & t_{i}^{-} \leq t<t_{i}
\end{array}\right.
$$

such that

$$
y_{i, t}=\left\{\begin{array}{ccc}
f_{i}\left(X_{i}\right)+\gamma_{i}+\alpha_{i}+\beta_{0, t}+\beta_{1, t}\left(X_{i}\right)+\varepsilon_{i, t} & \text { if } & t_{i} \leq t \leq t_{i}^{+} \\
f_{i}\left(X_{i}\right)+\alpha_{i}+\beta_{0, t}+\beta_{1, t}\left(X_{i}\right)+\varepsilon_{i, t} & \text { if } & t_{i}^{-} \leq t<t_{i}^{\prime}
\end{array}\right.
$$

where $X_{i}$ regroups the observable explanative variables constant over time such as gender, education level, year of birth or bad living conditions during childhood. The predetermined variables for the year before the event, such as $y_{i, t_{i}-1}$, activity dummy, sector dummy (public/private), working time dummy (full/part time) and type of labour contract (undetermined/fixed term) are also included. We lag these variables because the year before a disability provides a natural reference point for a DID estimation. These variables are regrouped in a vector $X_{i}$, and their effect on the outcome variable is denoted $f_{i}\left(X_{i}\right)$. The function $f_{i}$ is not restricted and can be specific to each individual. The following unobservable components of our model are similar to those of panel data models: $\alpha_{i}$ is the individual correlated effect and $\beta_{0, t}$ is the correlated time effect. In this paper, we generalise the standard panel data case by allowing a joint effect between the observable individual variables $X_{i}$ and unobservable time effects $\beta_{0, t}$, which we denote $\beta_{1, t}\left(X_{i}\right)$. This last point is important because the standard DID approach imposes the same time effect on the treated and not-treated individuals. The model in this paper is more general because we make this assumption only for the treated and not-treated individuals who share the same values for both individual variables. The last component of the outcome equation is the idiosyncratic error, denoted $\varepsilon_{i, t}$, which is uncorrelated with all other components. Without a loss of generality, we assume $\mathrm{E}\left(\varepsilon_{i, t}\right)=0$.

The effect of a disability on the outcome variable of individual $i$ is denoted $\gamma_{i}$. We seek to estimate the average value of the individual effects of the disability $\gamma_{i}$ on the disabled group, that is, the average effect of the treatment on the treated (ATT). In the first step of our method, we compute the before-after differences separately for the treated and control 
groups. The impact of a disability on performance $(y)$ one year after its occurrence is represented by the following equation:

$$
\begin{aligned}
& D_{i}^{T}= y_{i, t_{i}+1}-y_{i, t_{i}-1} \\
&=\alpha_{i}+\beta_{0, t_{i}+1}+\beta_{1, t_{i}+1}\left(X_{i}\right)+\gamma_{i}+f_{i}\left(X_{i}\right)+\varepsilon_{i, t_{i}+1} \\
& \quad-\left(\alpha_{i}+\beta_{0, t_{i}-1}+\beta_{1, t_{i}-1}\left(X_{i}\right)+f_{i}\left(X_{i}\right)+\varepsilon_{i, t_{i}-1}\right) \\
&=\gamma_{i}+\beta_{0, t_{i}+1}-\beta_{0, t_{i}-1}+\beta_{1, t_{i}+1}\left(X_{i}\right)-\beta_{1, t_{i}-1}\left(X_{i}\right)+\varepsilon_{i, t_{i}+1}-\varepsilon_{i, t_{i}-1} .
\end{aligned}
$$

This difference includes the effect of the disability, the effect of the time trend and the effect of white noise $\varepsilon$. Therefore, this first difference eliminates the effects of individual correlated effects $\alpha_{i}$ and of the additive part of the observable individual variables $f_{i}\left(X_{i}\right)$.

Consider the performance variation for all individuals $j$ that did not have a disability at time $t_{i}+1$. We consider the individuals $j$ who do not have a disability and individuals who will have a disability at a date $t_{j}>t_{i}+1$. These individuals define a comparison group whose composition varies over time, which explains why this method of matching is dynamic. This process implies that the same individual can be part of the treatment group and comparison group on different dates. In the comparison group, we consider individuals who have the same values for the explanatory variables $X_{i}$ (their twins). There are $N_{i}$ twins for each treated individual $i$, and their index belongs to the index set $J_{i}$ such that $j \in J_{i}$ and $\operatorname{card}\left(J_{i}\right)=N_{i}$. For the qualitative variables in $X_{i}$, we use an exact match, while for continuous variables (e.g., birth year), we use a calliper (e.g., 3 years). That is, we retain all twins for which the absolute difference in the continuous variable is below a set limit (called the calliper). We obtain the following average performance difference for the not-treated group:

$$
\begin{aligned}
& D_{J_{i}}^{N}=\frac{1}{N_{i}} \sum_{j \in J_{i}}\left(y_{j, t_{i}+1}-y_{j, t_{i}-1}\right) \\
& \quad=\frac{1}{N_{i}} \sum_{j \in J_{i}} \alpha_{j}+\beta_{0, t_{i}+1}+\beta_{1, t_{i}+1}\left(X_{j}\right)+f_{j}\left(X_{j}\right)+\varepsilon_{j, t_{i}+1}-\left(\alpha_{j}+\beta_{0, t_{i}-1}+\beta_{1, t_{i}-1}\left(X_{j}\right)+f_{j}\left(X_{j}\right)+\varepsilon_{j, t_{i}-1}\right) \\
& =\beta_{0, t_{i}+1}-\beta_{0, t_{i}-1}+\beta_{1, t_{i}+1}\left(X_{i}\right)-\beta_{1, t_{i}-1}\left(X_{i}\right)+\frac{1}{N_{i}} \sum_{j \in J_{i}}\left(\varepsilon_{j, t_{i}+1}-\varepsilon_{j, t_{i}-1}\right),
\end{aligned}
$$

where $X_{j}=X_{i}$.

Next, the difference of the differences for the treated group is computed as follows:

$$
\begin{aligned}
& \hat{\gamma}_{i}=D_{i}^{T}-D_{J_{i}}^{N} \\
& =y_{i, t_{i}+1}-y_{i, t_{i}-1}-\left(\frac{1}{N_{i}} \sum_{j \in J_{i}}\left(y_{j, t_{i}+1}-y_{j, t_{i}-1}\right)\right)
\end{aligned}
$$




$$
\begin{aligned}
=\gamma_{i}+\beta_{0, t_{i}+1} & -\beta_{0, t_{i}-1}+\beta_{1, t_{i}+1}\left(X_{i}\right)-\beta_{1, t_{i}-1}\left(X_{i}\right)+\varepsilon_{i, t_{i}+1}-\varepsilon_{i, t_{i}-1} \\
& -\left(\beta_{0, t_{i}+1}-\beta_{0, t_{i}-1}+\beta_{1, t_{i}+1}\left(X_{i}\right)-\beta_{1, t_{i}-1}\left(X_{i}\right)+\frac{1}{N_{i}} \sum_{j \in J_{i}}\left(\varepsilon_{j, t_{i}+1}-\varepsilon_{j, t_{i}-1}\right)\right) \\
=\gamma_{i}+\varepsilon_{i, t_{i}+1}- & \varepsilon_{i, t_{i}-1}-\frac{1}{N_{i}} \sum_{j \in J_{i}}\left(\varepsilon_{j, t_{i}+1}-\varepsilon_{j, t_{i}-1}\right) .
\end{aligned}
$$

We average these differences over the treated set $(i \in T)$. There are $N_{T}$ individuals in the treated set. Then, we obtain our estimator as follows:

$$
\begin{aligned}
& \hat{\gamma}=\frac{1}{N_{T}} \sum_{i \in T} \hat{\gamma}_{i} \\
& =\frac{1}{N_{T}} \sum_{i \in T} \gamma_{i}+\frac{1}{N_{T}} \sum_{i \in T}\left(\varepsilon_{i, t_{i}+1}-\varepsilon_{i, t_{i}-1}\right)-\frac{1}{N_{T}} \sum_{i \in T} \frac{1}{N_{i}} \sum_{j \in J_{i}}\left(\varepsilon_{j, t_{i}+1}-\varepsilon_{j, t_{i}-1}\right) .
\end{aligned}
$$

Under the standard assumption that white noise values share the mean $\mu_{\varepsilon}$, we obtain the following expression:

$$
\underset{\varepsilon}{\mathrm{E}}(\hat{\gamma})=\frac{1}{N_{T}} \sum_{i \in T} \gamma_{i},
$$

which is the empirical counterpart of $\gamma=\mathrm{E}\left(\gamma_{i} \mid i \in T\right)$. Therefore, the estimator is unbiased with an exact matching procedure.

This estimator can be generalised to any lag difference. If we wish to evaluate a middle term effect, we can compare the date $t_{i}-1$ to $t_{i}+d$, where $d \geq 1$. The only important change is in the comparison group. Now, we must examine twins that have no disability or experience a disability at a date $t_{j}>t_{i}+d$. Then, we define the long difference as $D_{i}^{T}(d)=y_{i, t_{i}+d}-y_{i, t_{i}-1}$ among the treated and $D_{J_{i}}^{N}(d)=1 / N_{i} \sum_{j \in J_{i}}\left(y_{j, t_{i}+d}-y_{j, t_{i}-1}\right)$ among the not-treated twins $\left(j \in J_{i}\right)$. Then, the ATT of the disability after $d$ periods is estimated as follows:

$$
\hat{\gamma}_{d}=\frac{1}{N_{T}} \sum_{i \in T}\left(D_{i}^{T}(d)-D_{J_{i}}^{N}(d)\right) .
$$

We estimate the standard errors utilising a block bootstrap with 1000 replications.

\section{Data and variables}

\section{III.1. The database}

The HLMH Survey was designed within the framework of a partnership between the Drees (the Ministry of Health) and the Dares (the Ministry of Labour), with scientific support from the Centre for Employment Studies (Cee). The National Institute of Statistics and Economic Studies (Insee) implemented the survey. The first wave, conducted in 2006, retrospectively questioned 14,000 persons aged between 20 and 74 living in ordinary households in France on their life paths (family, professional, and health status) and provided detailed descriptions of these dimensions at the time of the survey. The HLMH Survey was developed to meet two objectives: 
1. To better understand health determinants by defining health status in regards to labour market status and career path; and

2. To measure the influence of health status on an individual's career path, career risks and discrimination.

We present the variables used in this analysis of the effect of disability on labour market status below.

\section{III.2. Variables}

\section{III.2.1. Performance}

Our performance variable describes the annual labour market status of each individual. Specifically, this performance variable reflects the following four individual employment situations: employed in the public sector, employed in the private sector, unemployed (at least one year) or inactive. To estimate the effect of a disability on labour market status during, for example, the year following its occurrence $(t+1)$, we analyse the distribution of the treated group according to these four situations has been differently altered from that of not-treated. The decomposition of public and private employment is justified by differences in the professional integration of disabled persons. Nevertheless, the effect of a disability on total employment can be obtained by examining the sum of the effect on public employment and the effect on private employment.

\section{III.2.2. The treatment}

In the HLMH Survey, individuals can self-report disabilities and potential links to changes in their professional situations ${ }^{5}$. In this survey, 2095 respondents had experienced at least one disability by 2006. Disabilities are identified in various ways in the HLMH questionnaire and retrospective calendar (submitted with the questionnaire) and are reported regardless of whether they are explicitly linked to professional events. For example, the respondent might declare whether a disability marked his or her childhood or prevented the completion of education or job training. When describing professional trajectories, the respondent might declare whether a disability was disruptive. These inconveniences depend on the labour market status experienced during their career. For a complete employment period (1-5 years), people were asked whether a disability resulted in loss of employment or caused impairments or important changes in working conditions. For the current job (shortor long-term), individuals were only asked whether a disability resulted in loss of employment. For an unemployment period, people were asked whether a disability resulted in the end of job search. For a period of inactivity, people were asked whether a disability caused or extended it. In the health part of the survey, respondents who had already disclosed a life disturbance were asked whether a disability occurred and whether other periods of disability had been experienced.

\footnotetext{
${ }^{5}$ We assume that the potential justification skew is very limited. At first, we control for unobserved heterogeneity. Secondly, we match on lagged variables to avoid possible reverse causality. Finally, the set of matching variables including labour characteristics leads to conclude that the disability appears as a random event.
} 
Because we wish to examine the effect of disability on labour market status, we consider only individuals who have completed initial education. Of these individuals, 1,777 experienced at least one disability during the observation period.

The HLMH Survey enquired as to the origin of a disability, which, through a meticulous study of clearly formulated responses, enabled the correction of the raw data that had been coded "other". We identify the cause of a disability for $98 \%$ of the sample; accidents explain $41 \%$ of disabilities and one-third are due to an illness or health problem (see Table 1 in appendix 1).

The data also provide information about the start and end dates of disabilities. The absence of an end date indicates that the disability is on-going at the time of the survey. We estimate by maximum likelihood an absorbing state Weibull model in order to estimate the percentage of individuals with a permanent disability. The results are presented in Table 2 by gender and disability origin. This model reflects the fact that individuals who do not complete their initial education at the same age are not observed in similar periods (rightcensored data). The results presented in Table 2 reveal that approximately $50 \%$ of men and women reported a permanent disability. For individuals who experienced a first transitory disability, this disability lasted an average of 4.2 years for women and 3.6 years for men. If we distinguish by the origin of disability, the probability of irreversibility is very high when a disability occurs at birth. Indeed, $70 \%$ of disabilities that occur at birth are permanent.

In addition to their origin and duration, disabilities are also characterised by the age of onset. In Table 3, we observe that $23 \%$ of individuals experienced their first disability before they were 11 years old. However, as indicated in Figure 1, which presents the age density of the first disability, a significant proportion of these disabled individuals experienced their first disability at birth. Figure 1 indicates that the most likely ages for the occurrence of a disability are at birth, an accident at approximately 18 years old (particularly for young men), and maternity between the ages of 30 and 35. At 50 years old, the frequency of a first disability occurrence declines sharply and regularly because the probability of experiencing a first disability decreases as an individual ages.

We exclude disabilities that occurred before age 18. Indeed, lifestyle choices, notably education and professional choices, are made very early in the life cycle for people born with a disability. We also exclude disabilities beginning in 2006 because we cannot estimate their future impact on labour market status. Thus we include 1,008 disabled individuals in our sample. The study sample includes 6,734 individuals. Consequently, 5,726 individuals have not experienced a disability during their observation period. These individuals are part of the not-treated group. Because we implement a DID technique based on dynamic matching, the not-treated group consists both of individuals who have never experienced a disability and individuals who experience a disability later. Consequently, depending on when we measure the effect of disability on labour market status, the 1,008 disabled individuals can be part of either group. Among these 1,008 people, 920 only have long enough time periods to estimate at least one before-after difference. It is our reference sample for the estimations ${ }^{6}$.

\section{III.2.3. The matching variables}

\footnotetext{
${ }^{6}$ In table 5, the sample used for descriptive statistics is 937 whereas econometric method keeps 920 individuals. The gap between 937 and 920 is due to the impossibility to follow-up 17 individuals before/after the treatment.
} 
We examine exact matches of individuals who report a disability and individuals who have not experienced a disability at the date when the treated individual experienced their first disability. First, we consider socio-demographic characteristics, such as gender, education level and birth year ${ }^{7}$. Table 4 compares the gender socio-demographic characteristics of individuals who have experienced at least one disability. Around one quarter of disabled men reached a higher education, this proportion represents one third of the disabled women. The year before the disability, $94 \%$ of men are employed (of which 80 $\%$ in the private sector) against only $73 \%$ of women (of which $50 \%$ in the private sector). The type of contract better protects men (for instance more than $90 \%$ are concerned with a full time contract).

Second, we consider childhood living conditions, such as having been raised by their parents, whether having encountered problems in childhood (trauma, war, and violence at school or in their neighbourhoods, hard living conditions), whether having had problems affecting a relative during childhood (family conflict, death of a family member, a relative with serious health problems, long separation from a family member). Previous research indicates that these childhood variables might affect health status in adulthood [CASE et al., 2005; Trannoy et al., 2010; Duguet and Le Clainche, 2012 a,b, 2014]. Table 4 indicates that some difficult living conditions experienced during childhood increase the likelihood of experiencing a disability in adulthood.

We also consider matching variables that might vary over time. These variables describe the type of individual employment contract at $\mathrm{t}-1$, that is, permanent versus fixedterm contracts and part-time versus full-time positions. Indeed, a worker with a temporary contract at $\mathrm{t}-1$ who experienced a disability at time $\mathrm{t}$ might be unemployed or inactive at $\mathrm{t}+1$ due to the end of contract rather than the disability.

Finally, to address the endogeneity bias linked to the impact of employment on a disability, we consider the following matching variable: lagged performance describing the labour market status of individuals the year before the disability occurred.

\section{Results}

\section{IV.1. A stronger impact of disability on private employment}

The first part of Table 5 presents the average treatment effect on the treated (ATT) of disability on public employment, private employment, unemployment and inactivity during the five years following disability onset $(t+1, t+2, t+3, t+4$, and $t+5)$. Columns 1 and 2 , present the number of treated and matching rate, respectively. For each modality of the performance variable (i.e., employment in the private sector, employment in the public sector, unemployment and inactivity), the columns entitled "YO", "ATT" and "ASE", correspond to the average value of the corresponding modality among the treated one year before the treatment, average effect of the treatment on the treated and corresponding asymptotic standard error, respectively. If we refer to the first line of Table 5, we can observe that one year before the onset of a disability, $66.1 \%$ of individuals were employed in the private sector, $17.7 \%$ of individuals were employed in the public sector, $1.9 \%$ of individuals were unemployed and $14.3 \%$ of individuals were inactive. One year after the onset of a disability, $57.4 \%$ were still employed in the private sector (66.1-8.7), $16.6 \%$ were

\footnotetext{
${ }^{7}$ Because the year of birth is a continuous variable, we set a caliper equal to 3 years.
} 
employed in the public sector (17.7-1.1), $3.6 \%$ were unemployed $(1.9+1.7)$ and $23 \%$ were inactive $(14.3+8.2)^{8}$.

We calculate the absolute and relative effects of the onset of a disability on public and private employment. To evaluate whether a disability is more detrimental to private employment than to public employment, we consider the relative effect because the proportion of public employment to total employment is much lower than that of private employment. Indeed, the same reduction expressed in percentage points (the absolute effect) for public and private employment corresponds to more employees with disabilities leaving jobs in the public sector than in the private sector. The relative effects are displayed in the last two columns of Table 5.

A disability has a strong detrimental effect on private employment but has no significant effect on public employment during the five years following the onset of a disability. Indeed, the employment rate of private sector employees who have experienced a disability in $t$ decreases by 8.7 percentage points (pp.) at $t+1$ compared to $t-1$. In other words, $13.2 \%$ of the individuals employed in the private sector at $\mathrm{t}-1$ who experience a disability at $\mathrm{t}$ are no longer employed at $\mathrm{t}+1$. Moreover, the negative impact of disability on private employment increases slightly over time. This suggests that fewer individuals with disabilities who temporarily leave jobs at $t+1$ return to work over the following four years than those who leave their positions definitively at $t+1$.

As indicated in Table 5, the decrease in total employment of the treated of $9.8 \mathrm{pp}$. observed at $\mathrm{t}+1$ (the sum of the effects on both public and private employment) can be decomposed into an increase in the inactivity rate $(8.2 \mathrm{pp}$.$) and a statistically insignificant$ increase in the unemployment rate $(1.7 \mathrm{pp}$.). These results are consistent with those of LeCHNER and VAZQueZ-Alvarez [2011], who demonstrate that a disability diminishes the likelihood of being employed without increasing the probability of being unemployed and increases the probability of exiting the labour market. Therefore, the negative effect of a first disability observed within the private sector is not due to the ability of the private sector to dismiss employees with a disability while the public sector cannot.

It is likely that disabilities affecting public employees differ in duration and/or origin from those affecting private sector employees. Therefore, a stronger negative effect of a disability on private employment might be explained by these differences. To test this assumption, we examine the duration and origin of a disability.

\section{IV.2. A stronger impact of disability on private employment regardless of duration or origin}

The second part of Table 5 presents the effects of experiencing a transitory disability (one year or less), long-term disability (more than one year), accident or disease on labour market status. To distinguish between transitory and long-term disabilities, we rely on the existing research. Indeed, several econometric studies utilise data in which disabilities are considered health problems or disabilities that affect an individual's work for at least one year [BeNITEZ-SILVA et al., 2004; DRYDAKIS, 2010, 2012; TENNANT, 2012]. Moreover, the American

\footnotetext{
${ }^{8}$ We can interpret the absolute ATT as the difference, in percentage points, of the employment situation in $\mathrm{t}+1$ of the individuals having known a disability in $\mathrm{t}$ compared to their situation at $\mathrm{t}-1$ because, at $\mathrm{t}-1$, the employment situation (public or private employment, unemployment or inactivity) of the individuals who experience a disability at $t$ is identical to that of the twin who does not experience a disability at time $t$.
} 
Social Security Disability Insurance Benefits plan (SSDI) defines a disability as "the inability to engage in any substantial gainful activity (SGA) by reason of a medically determinable physical or mental impairment that is expected to last for a continual period of one year or more" [CAMPOLIETI AND RIDDELL, 2012]. Finally, the empirical results of some studies suggest that disability significantly affects individual labour market status when it lasts for longer than one year. For example, GaLARNEAU AND RADULESCU [2009] demonstrate that there are no significant differences in the labour supply (number of hours worked) of individuals who experienced a disability for one year and those who have not experienced a disability. This pattern does not hold when the disability lasts longer than one year.

Contrary to some studies, the results presented in Table 5 indicate that a transitory disability has a significant negative impact on private employment. One year after the occurrence of the disability, private employment is reduced by $4.3 \mathrm{pp}$., and, after five years, by $5.2 \mathrm{pp}$. In contrast, disability has no impact on public employment. Moreover, the decrease in the employment of private employees with transitory disabilities is explained by an increase of the rate of inactivity.

Long-term disabilities, which last longer than one year, exert more detrimental effects on employment than transitory disabilities (those lasting one year or less), indicating their greater severity. For example, one year after the occurrence of a long-term disability, private employment is reduced by $13.0 \mathrm{pp}$. while it is reduced by $4.3 \mathrm{pp}$. when the disability is transitory.

Contrary to transitory disability, long-term disability has a significant negative impact on public employment. However, the observed reduction in public employment is much smaller than that observed in private employment. Indeed, in the private sector, more than one in five individuals employed at $\mathrm{t}-1$ who experiences a long-term disability at $\mathrm{t}$ are no longer employed at $t+1$ while this proportion is only $14.5 \%$ for the public sector. Finally, contrary to transitory disability, the decrease in employment observed among employees with a long-term disability is partly explained by an increase in their unemployment rate. This pattern might indicate that some people with long term disabilities are "disabled enough" to be dismissed but not enough to transition towards inactivity.

When the origin of the disability is accident, it affects the employment rate only in the private sector. In addition, the decrease in private sector employment of individuals with disabilities whose origin is accident can be totally explained by an exit from the labour market (inactivity).

Compared to disability resulting from an accident, disability due to disease is more detrimental to employment, particularly for private employment. Indeed, $23.2 \%$ of private sector employees who are disabled by a disease at time $t$ are not employed at $t+1(8.6 \%$ for private sector employees disabled by an accident), a proportion that is nearly twice as high as in the public sector (12.4\%).

The results presented in the second part of Table 5 indicate that differences in the type of disability affecting employees in the public and private sectors do not explain the more detrimental effect of disability on private employment. This public-private difference might be explained by differences in the composition of workforce of each sector. 


\section{IV.3. A stronger impact of disability on private employment regardless of gender and education level}

It is well known that in France women are overrepresented in the public sector and constitute a smaller share of the private sector workforce. According to the Annual Report on Civil Service, women held $59.8 \%$ of jobs in the public sector in 2010. In comparison, the percentage of women in the private sector was approximately $39 \%$.

The first part of Table 6 presents the effect of disability on labour market status by gender during the subsequent five years. The results reveal that the stronger effect of disability on private employment is not explained by a difference in workforce gender composition between the private and public sectors. Indeed, while the onset of disability decreases the employment of both male and female private sector employees, disability has no significant impact on the employment of men and women in the public sector.

In the private sector, the onset of disability is much more detrimental to the employment for women than for men. Indeed, more than one in four women who experienced a disability at time $t$ are not employed five years after, while only $11.9 \%$ of men are not employed at that time.

Several explanations might exist for this gender difference in labour market performance after the onset of disability.

At first, female disabilities (such as chronic disease or psychiatric disorders) are more penalizing for professional paths than those relating to men (accidents). We know that chronic diseases are particularly damaging for employment. In order to explain the publicprivate difference, psychiatric disabled people are more often employed in the public sector than in private one [LE CLAINCHE, 2007) due to better protection in the public sector. In addition, with similar health shock, return to work is more difficult for women for instance following Diabetes [LATIF, 2009] or a cancer [MARINo et al., 2013].

Secondly, women have a greater preference for health. Before and after a given health shock, women invest more in their own health than men (in prevention and care goods). This health preference is convergent with a lower depreciation rate of health capital for women than for men and a better life expectancy. In addition, the utility associated with leisure is greater for women in poor health, taking into account the value attributed to domestic work. Therefore, work disutility following a health shock is greater for women [PARINGER, 1983].

For both male and female private sector employees, the reduction in employment is mainly due to an increase in the inactivity rate.

Public sector employees also report higher levels of education than private sector employees do. Education is likely to protect people against the negative effects of disability at work. For example, it is well known that the least educated people have fewer resources when they are disabled because they have less access to information to help access or maintain employment [FANTONI-QUINTON AND FRIMAT 2011[. Skilled employees are more likely to benefit from the OETH measures in the private sector [AMIRA, 2008].

The second part of Table 6 presents the effect of disability on labour market status by three levels of education: primary, secondary and above $A$ level. In the private sector, the results highlight the protective role of education in the face of the negative effects of a disability on labour market participation described in previous research (see, for example, JONES, LATREILLE AND SLOAN, 2006). Indeed, one year after the occurrence of disability, employment rate of private sector employees having experienced a disability at time $t$ 
decreases by 12.9 pp., $8.8 \mathrm{pp}$. and $4.5 \mathrm{pp}$. among employees with primary, secondary and $A$ level or above educational levels, respectively. In the public sector, we observe that the occurrence of disability does not significantly affect employment of individuals with either primary or A level or above education. Although the significance is low, the employment rate of public sector employees with a secondary level of education decreases during the five years after the onset of a disability.

\section{IV.4. A stronger impact of disability on private employment regardless of the age at first disability}

As indicated by several studies, a disability produces different effects on the labour market status of individuals depending on when in their working life the disability occurred [PELKOWSKI AND BeRgeR, 2004; Duguet AND Le ClainCHE, 2014]. The effects of a disability can be very important early in a career, including the potential loss of professional opportunities, but disabilities that occur later in career can be combined with the effects of aging and lead to early exits from the labour market. The magnitude of these effects is difficult to determine according to the place in the life cycle.

Table 7 compares the effect of disability on the labour market status of individuals younger or older than the median age. In our sample, the median age is 36 years. This distinction is required due to the small sample size, which prevents us from assessing the effect of disability for small age groups (for example, seniors). In the private sector, the results indicate that the effect of disability is much more detrimental to the labour market status of individuals when it occurs during the second half of working life. Indeed, private sector employees are almost three times more likely to be unemployed at $t+3, t+4$ and $t+5$ (two times more in $t+1$ and $t+2$ ) when they are over 36 than when they are under 36 years old. In the public sector, disability is only detrimental when it occurs beyond the median age, but this effect is much smaller than that observed in the private sector.

Three main explanations can be developed for public and private sector differences when disability occurs during the second half of a career rather than at the beginning.

At first, in France, the decreasing age of retirement, the persistence of both early retirement and job seeking exemptions until July 2008, would all appear to enable employees with poor health to exit early from the labour market. BARNAY [2010] shows that a significant proportion of 55-59 year old people with disabilities have job seeking exemptions which benefit from unhealthy people in the private sector.

Then, we assume that facing a similar disability, people's labour supply does not respond identically depending on the work environment and job satisfaction, especially for old workers ( 50 years old and over). According to some studies, work conditions seem to be less harsh, and even painful, in the public sector than in the private one. For instance, COUTROT AND ROUXEL [2011] underlines that in the public sector, workers 50 years old and over are, on average, less often exposed to repetitive physical pain at work than in the private sector.

Finally, the type of disability affecting old workers may not be similar depending on the sector and could be more penalizing in terms of job retention in the private sector. Indeed, we know that risk accumulation (i.e. having been exposed to physical pains for at least 15 
years) is more likely to concern employees in the private sector than those in the public one [BAHU, Mermilliod AND VolKoff, 2011].

We also observe that the detrimental effect of disability on employment significantly increases over time when disability occurs for individuals who are older than the median age. This pattern suggests that the later a disability occurs during a career, the more detrimental it is to employment. Other explanations might account for this phenomenon. First, the nature of a disability might differ depending on the age of occurrence. For example, young people are more likely to experience a disability from an accident while older people experience more disability from disease. Moreover, over the life cycle, comorbidities may amplify the effects of disabilities. Second, disability occurring at older ages can be particularly incapacitating and prevent job retention. Third, as more individuals approach retirement age, the opportunity cost of exiting employment decreases.

Because the importance of these explanations might vary by gender and women are overrepresented in the public sector, we conducted another analysis distinguishing by age and gender. In our study sample, the median age is 39 years for women and 33 years for men. The results are provided in Table 8. For men and women, disability is more detrimental to employment when it occurs during the second half of working life, i.e., beyond the median age. Disabilities that occur beyond the median age are more detrimental to women than to men. This difference is explained by the fact that we consider disabilities that occur later in women's working lives. Indeed, the median age of women is six years older than that of men. The differences between the public and private sectors based on the relative effects indicate that these differences are more pronounced for women than for men, especially when the disability occurs after the median age. Thus, when a disability occurs after age 38 , $38.6 \%$ of women in the private sector who experience a disability are unemployed five years later. This proportion rises to $15.9 \%$ for female employees in the public sector. These results confirm the particularly protective role of the public sector.

\section{Conclusion}

This paper examines the causal effect of a disability on subsequent labour market status by distinguishing between public and private employment. To address this question, we implement a DID approach combined with an exact, dynamic matching method. To the best of our knowledge, the implementation of a dynamic treatment approach, which implies that individuals who have not been treated at a point in time can receive treatment later, is novel in the field of health economics. Actually, the dynamic treatment approach is generally applied in labour economics, especially in the context of the program evaluation of active labour market policies (see for example, SIANESI [2008]). We use the retrospective calendar from the HLMH Survey, which enables us to build an individual/year panel and identifies the exact date of disability onset. Then, we evaluate the causal effect of a disability on private sector employment, public sector employment, unemployment and inactivity during the subsequent five years.

Our main result is the strong detrimental effect of a disability on private employment but no significant impact on public employment during the five years following a disability occurrence. This difference is not explained by the fact that the private sector, unlike the public sector, can dismiss employees with a disability. We also conducted a sensitivity analysis to examine the robustness of our results to public and private sector differences in 
terms of type of disability and workforce composition. The stronger detrimental effect of a disability on private employment persists regardless of duration or origin. Moreover, our results are robust to an analysis of gender and level of education. Finally, whereas the public sector provides more early retirement schemes than the private sector, we demonstrate that the occurrence of disability is more detrimental to private employment than to public employment even when the disability occurs during the second half of a career regardless of employee gender.

In summary, following the occurrence of a disability, public sector employees remain employed more frequently than do their private sector counterparts. Future research should compare the dynamics of public/private transitions between individuals who are not disabled and individuals who have experienced a disability to confirm the protective role of the public sector. 


\section{References}

Akashi-Ronquest N., Carrillo P., Dembling B., Stern S. (2011) "Measuring the Biases in Self-Reported Disability Status: Evidence from Aggregate Data" Applied Economics Letters, 18(11), p. 1053-1060. [4, 5]

AMIRA S. (2008), "L'obligation d'emploi des personnes handicapées. Une nouvelle loi à partir de 2006 ", Premières Synthèses Dares n46.1.[13]

Bahu, M., Mermilliod, C., Volkoff, S. (2011), "Conditions de travail pénibles au cours de la vie professionnelle, et état de santé après 50 ans," L'état de santé de la population en France: Rapport 2011, Collection Études et statistiques, Drees, p. 39-55. [15]

Barnay, T. (2010), "In Which Ways do Unhealthy People Older than 50 Exit the Labour Market in France?", European Journal of Health Economics, 11(2), p. 127-140. [14]

Benitez-Silva, H., Buchinsky, M., Man Chan, H., Cheidvasser, S., Rust, J. (2004), "How Large is the Bias in Self-Reported Disability?", Journal of Applied Econometrics, 19, p. 649-670. [3, 11]

CAI, L. (2009) "Is Self-Reported Disability Status Endogeneous to Labour Force Status?", Applied Economic Letters, 16(5), p. 459-464. [3]

CAMPolietI, M., RIDDELL, C. (2012) "Disability Policy and the Labor Market: Evidence from a Natural Experiment in Canada," 1998-2006, Journal of Public Economics, 96, p. 306-316. [3, 12]

CASE, A., Fertig, A., PAXSON, C. (2005) "The Lasting Impact of Childhood Health and Circumstance," Journal of Health Economics, 24, p. 365-389. [10]

Coutrot, T., Rouxel, C. (2011) "Emploi et santé des seniors durablement exposés à des pénibilités physiques au cours de leur carrière" DARES Analyses, 020. 8 p. [15]

DRYDAKIS, N. (2010), "Health Impairments and Labour Market Outcomes", European Journal of Health Economics, 11(5), p. 457-469. [11]

DRYDAKIS, N. (2012), "Health Impaired Employees' Job Satisfaction New Evidence from Athens, Greece", Applied Economics Letters, 19(8), p. 789-793. [11]

Duguet E., Le Clainche C. (2014), "The Effect of Non-Work Related health Events on Career Outcomes: An Evaluation in the French Labor Market, Revue d'Economie Politique 124 (3), pp. $437-$ 465. $[3,10,14]$

Duguet E., LE ClAinCHE C. (2012a), "The Impact of Health Events on Labor Market Individual Histories: The Message from Differences in Difference with Exact Matching", Document de travail CEE, $\mathrm{n}^{\circ} 156$, mai. 19 p. $[3,10]$

Duguet E., Le Clainche C. (2012b), "Chronic Illnesses and Injuries: An Evaluation of their Impact on Occupations and Revenues", Document de travail CEE, $n^{\circ} 155$. p. $[3,10]$

Duguet E., Le Clainche C. (2012c), "Une évaluation de l'impact de l'aménagement des conditions de travail sur la reprise du travail après un cancer," Working Papers 12-25, LAMETA, University of Montpellier., à paraître dans Revue Economique [2]

DWYeR, D., MitCHeLL, O. (1999), "Health Problems as Determinants of Retirement: are Self-Rated Measures Endogenous?", Journal of Health Economics, 18(2), p. 173-193. [3]

FANTONI-QUINTON S., FRIMAT P. (2011), "Maintien au travail et maladie: un exemple d'accompagnement individualisé en région Nord ", santé publique, vol. 23, pp. 251-259. [14]

Galarneau, D., Radulescu, M. (2009), "Employment Among the Disabled", Perspectives on Labour and Income, 10(5), p. 5-15. [12] 
GanNon, B. (2009) "The Influence of Economic Incentives on Reported Disability Status", Health Economics, 18(7): 2009, p. 743-759. [3]

GarciA-Gomez, P. (2011), "Institutions, Health Shocks and Labour Outcomes Across Europe," Journal of Health Economics, 30(1), p. 200-213. [3, 5]

JONES, M. (2011), "Disability, Employment and Earnings: An Examination of Heterogeneity," Applied Economics, 43(8), p. 1001-1017. [3]

Jones, M., Latreille, P., Sloane, P. (2006), "Disability, Gender and the Labour Market in Wales", Regional Studies, 40 (8), p. 823-845. [14]

LATIF, E. (2009), The impact of diabetes on employment in Canada. Health Econ., 18: 577-589. doi: 10.1002/hec.1390. [13]

Le Clainche, C., (2007) "Discrimination in the Access to Employment for the Persons with a "Psychic Handicap " : What can Positive Discrimination do ? The Case of France", The Journal of Mental Health Policy and Economics, vol. 10, s. 1, March 2007, pp. 24-25. [13]

LeChneR, M., Vazquez-Alvarez, R. (2011), "The Effect of Disability on Labour Market Outcomes in Germany", Applied Economics, 43(4), p. 389-412. [3, 5, 11]

Lindeboom, M., KeRKHOFS, M. (2002) "Subjective Health Measures, Reporting Errors and the Endogenous Relationship Between Health and Work" IZA Discussion Papers, 457, 40 p. [3]

Lindeboom, M., Nozal A.L, DeR KlaAuW, B. (2006), "Disability and Work: the Role of Health Shocks and Childhood Circumstances", Tinbergen Institute, Tinbergen Institute Discussion Papers: 06-039/3. [3]

MARIE, O., VAlL-CASTEllo, J. (2012), "Measuring the (Income) Effect of Disability Insurance Generosity on Labour Market Participation," Journal of Public Economics, 96(1), p. 198-210. [3]

Marino P, Teyssier L.S., Malavolti L., AND Le Corroller-Soriano A-G (2013), "Sex differences in the return-to-work process of cancer survivors 2 years after diagnosis: results from a large French population-based sample"., J CLIN ONCOL. 2013 APR 1;31(10):1277-84. doi: 10.1200/JCO.2011.38.5401. Epub 2013 Jan 28. [13]

Moller-DANo A.M. (2005). "Road Injuries and Long Run Effects on Income and Employment". Health Economics, 14 (9) : 955-970. [3, 5]

MitRA, S. (2009), "Disability Screening and Labor Supply: Evidence from South Africa," American Economic Review, 99(2), p. 512-516. [3]

NGUYEN K.-N., ULRICH V. (2008), " L'accès à l'emploi des personnes handicapées en 2007 », Premières Synthèses, Dares $n^{\circ}$. 47.1. [2]

PARINGER, L. (1983). "Women and absenteeism: Health or economics?" American Economic Review, 73, 123-27. [13]

PELKOWSKI, J. E. \& BERGER, M. C. (2004). " The Impact of Health on Employment, Wages, and Hours Worked Over the Life Cycle". Quarterly Review of Economics and Finance, 44(1), 102-21.SIANESI B. (2008), "Differential effects of Swedish active labor market programs for the unemployed", Labour Economics, 12(3), p. 370-399.

StAUBLI, S. (2011), "The Impact of Stricter Criteria for Disability Insurance on Labor Force Participation", Journal of Public Economics, 95(9-10), p. 1223-1235. [3]

TENNANT, J. (2012), "Disability, Employment and Income: are Iraq/Afghanistan-era US Veterans Unique ?", Monthly Labor Review, 135(8), p. 3-10. [11]

Trannoy, A., TUbeuf, S., Jusot, F., Devaux, M. (2010), "Inequality of Opportunities in Health in France: a First Pass," Health Economics, 19(8), p. 921-938. [10] 


\section{Appendix}

Table 1: DISABILITY ORIGIN

\begin{tabular}{lcc} 
Origin of the disability & Raw Data & Corrected Data \\
\hline An illness or health problem & $20.9 \%$ & $33.8 \%$ \\
A malformation or an accident at birth & $12.9 \%$ & $14.5 \%$ \\
An accident & $37.5 \%$ & $41.1 \%$ \\
Ageing & $4.0 \%$ & $4.1 \%$ \\
Consequences of medical care or surgery & $4.0 \%$ & $4.6 \%$ \\
Other & $20.8 \%$ & $1.9 \%$ \\
\hline
\end{tabular}

Sample: Individuals that have experienced at least one disability and have completed their initial education ( $N=1777)$. 
Table 2: DURATION OF THE FIRST DISABILITY

\begin{tabular}{|c|c|c|c|}
\hline Sub-samples & $\pi$ & $H$ & $\alpha$ \\
\hline \multicolumn{4}{|l|}{ Women } \\
\hline Parameters' estimates & 0.503 & 0.273 & 0.880 \\
\hline Duration average & & 4.18 & \\
\hline Duration median & & 2.89 & \\
\hline \multicolumn{4}{|l|}{ Men } \\
\hline Parameters' estimates & 0.499 & 0.300 & 0.910 \\
\hline Duration average & & 3.63 & \\
\hline Duration median & & 2.51 & \\
\hline \multicolumn{4}{|l|}{ Origin: Accident } \\
\hline Parameters' estimates & 0.423 & 0.360 & 0.963 \\
\hline Duration average & & 2.84 & \\
\hline Duration median & & 1.97 & \\
\hline \multicolumn{4}{|l|}{ Origin: Illness } \\
\hline Parameters' estimates & 0.515 & 0.219 & 0.935 \\
\hline Duration average & & 4.95 & \\
\hline Duration median & & 3.44 & \\
\hline \multicolumn{4}{|l|}{ Origin: Birth } \\
\hline Parameters' estimates & 0.701 & 0.104 & 0.958 \\
\hline Duration average & & 10.41 & \\
\hline Duration median & & 7.22 & \\
\hline \multicolumn{4}{|l|}{ Origin: Other } \\
\hline Parameters' estimates & 0.348 & 0.197 & 0.730 \\
\hline Duration average & & 8.47 & \\
\hline Duration median & & 5.61 & \\
\hline
\end{tabular}

Sample: Individuals that have experienced at least one disability and have completed their initial education ( $\mathrm{N}=1777$ ).

Note: The results are obtained from the estimation of absorbing state Weibull model :

$$
\text { Survival function : } S(t)=\pi+(1-\pi) \exp \left(-h t^{\alpha}\right)
$$

$\pi$ : Proportion of the population with a permanent disability

All parameters are significant at conventional levels. The averages and medians apply to the individuals that exit from disabilities $46.5 \%$ of the disability durations are right-censored. Maximum likelihood estimates.

Reading example: $50,3 \%$ of women who experienced a first disability never come out. Among women who have experienced a transitory disability, the duration of this disability was on average 4,18 years and, for $50 \%$ of them, this disability lasted less than 2,89 years. 
0 to 10 years

11 to 20 years

21 to 40 years

Over 40 years

$26.1 \%$

Sample: Individuals that have experienced at least one disability and have completed their initial education ( $\mathrm{N}=1777)$.

Figure 1: AGE DENSITY AT FIRST DISABILITY

Parzen-Rosenblatt kernel density estimator, with a Gaussian kernel

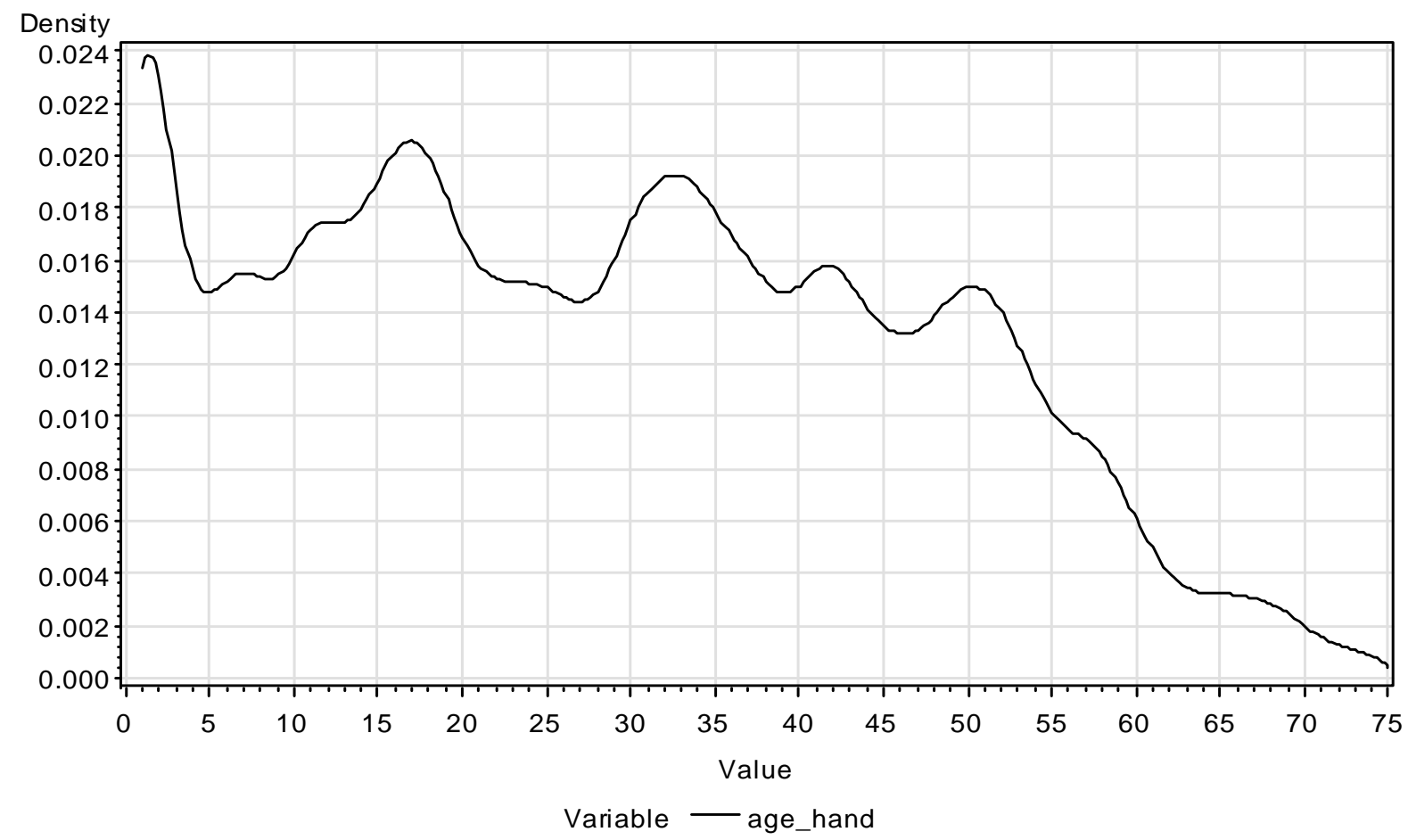

Sample: Individuals that have experienced at least one disability and have completed their initial education ( $\mathrm{N}=1777)$. 
Table 4: Disabled People' Average Characteristics

\begin{tabular}{|c|c|c|c|}
\hline & Women & Men & Total \\
\hline \multicolumn{4}{|l|}{ Time constant variables } \\
\hline \multicolumn{4}{|l|}{ Education: } \\
\hline Primary & $29.3 \%$ & $26.3 \%$ & $27.7 \%$ \\
\hline Secondary & $38.4 \%$ & $48.2 \%$ & $43.4 \%$ \\
\hline Above A level & $32.3 \%$ & $25.5 \%$ & $28.8 \%$ \\
\hline Raised by their familly & $86.2 \%$ & $84.1 \%$ & $85.2 \%$ \\
\hline Bad childhood living conditions & $67.9 \%$ & $57.0 \%$ & $62.3 \%$ \\
\hline \multicolumn{4}{|l|}{$\begin{array}{l}\text { Time varying variables one year } \\
\text { before the disability }\end{array}$} \\
\hline \multicolumn{4}{|l|}{ Activity : } \\
\hline Public sector & $23.6 \%$ & $13.4 \%$ & $18.4 \%$ \\
\hline Private sector & $49.3 \%$ & $80.4 \%$ & $65.2 \%$ \\
\hline Inactivity or unemployment & $27.1 \%$ & $6.3 \%$ & $16.4 \%$ \\
\hline \multicolumn{4}{|l|}{ Type of labour contract: } \\
\hline Full time & $59.2 \%$ & $91.2 \%$ & $75.6 \%$ \\
\hline Long term & $46.5 \%$ & $59.7 \%$ & $53.3 \%$ \\
\hline Age & 39.9 & 34.9 & 37.4 \\
\hline $\begin{array}{l}\text { Number of observations } \\
\%\end{array}$ & $\begin{array}{c}458 \\
48.9 \%\end{array}$ & $\begin{array}{c}479 \\
51.1 \%\end{array}$ & $\begin{array}{c}937 \\
100.0 \%\end{array}$ \\
\hline
\end{tabular}


Table 5: Effect of a disability on labour market status by disability length and origin

\begin{tabular}{|c|c|c|c|c|c|c|c|c|c|c|c|c|c|c|c|c|}
\hline \multirow{2}{*}{ Health event time } & \multirow{2}{*}{ Treated } & \multirow{2}{*}{ Matched } & \multicolumn{3}{|c|}{ Employment in the private sector } & \multicolumn{3}{|c|}{ Employment in the public sector } & \multicolumn{3}{|c|}{ Unemployment } & \multicolumn{3}{|c|}{ Inactivity } & \multirow{2}{*}{$\begin{array}{l}\text { Private sector } \\
\text { relative ATT } \\
\text { 2)/(1) }\end{array}$} & \multirow{2}{*}{$\begin{array}{c}\text { Public sector } \\
\text { relative ATT } \\
\text { (4)/(3) }\end{array}$} \\
\hline & & & YO (1) & ATT (2) & ASE & YO (3) & ATT (4) & ASE & Yo & ATT & ASE & Yo & ATT & ASE & & \\
\hline \multicolumn{17}{|l|}{ All disabilitys } \\
\hline$T+1$ & 920 & $95.3 \%$ & 0.661 & $-0.087^{*}$ & 0.013 & 0.177 & $-0.011+$ & 0.006 & 0.019 & $0.017^{*}$ & 0.007 & 0.143 & $0.082^{*}$ & 0.011 & $-13.2 \%$ & $-6.3 \%$ \\
\hline$T+2$ & 877 & $95.1 \%$ & 0.664 & $-0.096^{*}$ & 0.015 & 0.181 & -0.010 & 0.008 & 0.017 & $0.015+$ & 0.008 & 0.138 & $0.091^{*}$ & 0.013 & $-14.5 \%$ & $-5.6 \%$ \\
\hline$T+3$ & 832 & $95.1 \%$ & 0.664 & $-0.101^{*}$ & 0.015 & 0.183 & -0.013 & 0.009 & 0.016 & $0.025^{*}$ & 0.009 & 0.137 & $0.090^{*}$ & 0.014 & $-15.3 \%$ & $-7.3 \%$ \\
\hline$T+4$ & 784 & $95.2 \%$ & 0.672 & $-0.110^{*}$ & 0.016 & 0.181 & $-0.018^{*}$ & 0.009 & 0.016 & $0.023^{*}$ & 0.009 & 0.131 & $0.105^{*}$ & 0.015 & $-16.3 \%$ & $-9.8 \%$ \\
\hline$T+5$ & 745 & $94.9 \%$ & 0.662 & $-0.111^{*}$ & 0.016 & 0.187 & -0.016 & 0.011 & 0.017 & $0.025^{*}$ & 0.010 & 0.134 & $0.102^{*}$ & 0.015 & $-16.8 \%$ & $-8.8 \%$ \\
\hline \multicolumn{17}{|c|}{ Length : 1 year or less } \\
\hline$T+1$ & 454 & $95.4 \%$ & 0.707 & $-0.043^{*}$ & 0.016 & 0.171 & 0.005 & 0.009 & 0.021 & -0.004 & 0.009 & 0.102 & $0.043^{*}$ & 0.014 & $-6.1 \%$ & $2.7 \%$ \\
\hline$T+2$ & 429 & $95.1 \%$ & 0.713 & $-0.036+$ & 0.019 & 0.174 & 0.003 & 0.011 & 0.017 & -0.003 & 0.011 & 0.096 & $0.036^{*}$ & 0.016 & $-5.0 \%$ & $1.7 \%$ \\
\hline$T+3$ & 409 & $95.4 \%$ & 0.718 & $-0.036+$ & 0.019 & 0.172 & -0.001 & 0.012 & 0.018 & -0.004 & 0.011 & 0.092 & $0.041^{*}$ & 0.017 & $-5.0 \%$ & $-0.8 \%$ \\
\hline$T+4$ & 384 & $95.3 \%$ & 0.724 & $-0.037+$ & 0.021 & 0.169 & -0.006 & 0.014 & 0.016 & -0.004 & 0.012 & 0.090 & $0.047^{*}$ & 0.018 & $-5.1 \%$ & $-3.5 \%$ \\
\hline$T+5$ & 359 & $95.0 \%$ & 0.710 & $-0.052^{*}$ & 0.021 & 0.179 & -0.005 & 0.015 & 0.018 & 0.008 & 0.013 & 0.094 & $0.050^{*}$ & 0.019 & $-7.4 \%$ & $-2.9 \%$ \\
\hline \multicolumn{17}{|c|}{ Length : More than 1 year } \\
\hline$T+1$ & 466 & $95.3 \%$ & 0.617 & $-0.130^{*}$ & 0.019 & 0.182 & $-0.027^{*}$ & 0.008 & 0.018 & $0.037^{*}$ & 0.011 & 0.182 & $0.120^{*}$ & 0.019 & $-21.0 \%$ & $-14.5 \%$ \\
\hline$T+2$ & 448 & $95.3 \%$ & 0.616 & $-0.151^{*}$ & 0.021 & 0.187 & $-0.023^{*}$ & 0.010 & 0.019 & $0.031^{*}$ & 0.012 & 0.178 & $0.144^{*}$ & 0.020 & $-24.5 \%$ & $-12.5 \%$ \\
\hline$T+3$ & 423 & $95.0 \%$ & 0.609 & $-0.162^{*}$ & 0.022 & 0.194 & $-0.025^{*}$ & 0.012 & 0.017 & $0.050^{*}$ & 0.014 & 0.179 & $0.138^{*}$ & 0.021 & $-26.7 \%$ & $-13.7 \%$ \\
\hline$T+4$ & 400 & $95.3 \%$ & 0.619 & $-0.179^{*}$ & 0.023 & 0.192 & $-0.028^{*}$ & 0.013 & 0.018 & $0.046^{*}$ & 0.015 & 0.171 & $0.161^{*}$ & 0.023 & $-28.9 \%$ & $-12.6 \%$ \\
\hline$T+5$ & 386 & $95.1 \%$ & 0.616 & $-0.163^{*}$ & 0.023 & 0.193 & $-0.027^{*}$ & 0.014 & 0.019 & $0.039^{*}$ & 0.014 & 0.172 & $0.151^{*}$ & 0.024 & $-26.5 \%$ & $-14.1 \%$ \\
\hline \multicolumn{17}{|l|}{ Origin : Accident } \\
\hline$T+1$ & 507 & $95.3 \%$ & 0.714 & $-0.061^{*}$ & 0.016 & 0.172 & -0.002 & 0.008 & 0.025 & 0.003 & 0.010 & 0.089 & $0.061^{*}$ & 0.014 & $-8.6 \%$ & $-1.3 \%$ \\
\hline$T+2$ & 481 & $95.2 \%$ & 0.718 & $-0.067^{*}$ & 0.018 & 0.177 & 0.003 & 0.011 & 0.022 & -0.001 & 0.011 & 0.083 & $0.065^{*}$ & 0.016 & $-9.4 \%$ & $1.9 \%$ \\
\hline$T+3$ & 459 & $95.6 \%$ & 0.720 & $-0.066^{*}$ & 0.020 & 0.175 & -0.002 & 0.012 & 0.023 & -0.002 & 0.011 & 0.082 & $0.069^{*}$ & 0.017 & $-9.1 \%$ & $-0.9 \%$ \\
\hline$T+4$ & 431 & $95.6 \%$ & 0.723 & $-0.064^{*}$ & 0.019 & 0.175 & -0.006 & 0.013 & 0.022 & -0.003 & 0.012 & 0.080 & $0.072^{*}$ & 0.018 & $-8.8 \%$ & $-3.5 \%$ \\
\hline$T+5$ & 412 & $95.4 \%$ & 0.715 & $-0.073^{*}$ & 0.020 & 0.181 & -0.009 & 0.015 & 0.023 & 0.002 & 0.011 & 0.081 & $0.080^{*}$ & 0.019 & $-10.2 \%$ & $-4.8 \%$ \\
\hline \multicolumn{17}{|l|}{ Origin : Disease } \\
\hline$T+1$ & 326 & $94.8 \%$ & 0.589 & $-0.137^{*}$ & 0.022 & 0.191 & $-0.024^{*}$ & 0.010 & 0.013 & $0.039^{*}$ & 0.013 & 0.207 & $0.122^{*}$ & 0.021 & $-23.2 \%$ & $-12.4 \%$ \\
\hline$T+2$ & 314 & $94.6 \%$ & 0.589 & $-0.150^{*}$ & 0.024 & 0.195 & $-0.027^{*}$ & 0.011 & 0.013 & $0.036^{*}$ & 0.014 & 0.202 & $0.141^{*}$ & 0.024 & $-25.5 \%$ & $-13.9 \%$ \\
\hline$T+3$ & 295 & $93.9 \%$ & 0.581 & $-0.164^{*}$ & 0.027 & 0.202 & $-0.023+$ & 0.013 & 0.011 & $0.059^{*}$ & 0.018 & 0.206 & $0.128^{*}$ & 0.025 & $-28.2 \%$ & $-11.4 \%$ \\
\hline$T+4$ & 281 & $94.3 \%$ & 0.592 & $-0.184^{*}$ & 0.027 & 0.196 & $-0.027^{*}$ & 0.013 & 0.011 & $0.051^{*}$ & 0.016 & 0.200 & $0.160^{*}$ & 0.027 & $-31.1 \%$ & $-13.8 \%$ \\
\hline$T+5$ & 267 & $93.6 \%$ & 0.584 & $-0.170^{*}$ & 0.028 & 0.200 & -0.019 & 0.015 & 0.012 & $0.050^{*}$ & 0.017 & 0.204 & $0.139^{*}$ & 0.028 & $-29.0 \%$ & $-9.7 \%$ \\
\hline
\end{tabular}


Table 6: Effect of a disability on labour market status by gender and education level

\begin{tabular}{|c|c|c|c|c|c|c|c|c|c|c|c|c|c|c|c|c|}
\hline \multirow{2}{*}{ Health event time } & \multirow{2}{*}{ Treated } & \multirow{2}{*}{ Matched } & \multicolumn{3}{|c|}{ Employment in the private sector } & \multicolumn{3}{|c|}{ Employment in the public sector } & \multicolumn{3}{|c|}{ Unemployment } & \multicolumn{3}{|c|}{ Inactivity } & \multirow{2}{*}{$\begin{array}{c}\text { Private } \\
\text { sector } \\
\text { relative ATT } \\
(2) /(1)\end{array}$} & \multirow{2}{*}{$\begin{array}{c}\text { Public } \\
\text { sector } \\
\text { relative ATT } \\
(4) /(3)\end{array}$} \\
\hline & & & Y0 (1) & ATT (2) & ASE & YO (3) & ATT (4) & ASE & Yo & ATT & ASE & Yo & ATT & ASE & & \\
\hline \multicolumn{17}{|l|}{ Women } \\
\hline$T+1$ & 452 & $99.3 \%$ & 0.494 & $-0.096^{*}$ & 0.017 & 0.236 & -0.010 & 0.009 & 0.027 & $0.023^{*}$ & 0.011 & 0.243 & $0.082^{*}$ & 0.017 & $-19.3 \%$ & $-4.1 \%$ \\
\hline$T+2$ & 428 & $95.3 \%$ & 0.498 & $-0.090^{*}$ & 0.021 & 0.225 & -0.012 & 0.012 & 0.029 & 0.008 & 0.013 & 0.248 & $0.094^{*}$ & 0.021 & $-18.0 \%$ & $-5.4 \%$ \\
\hline$T+3$ & 406 & $95.3 \%$ & 0.499 & $-0.091^{*}$ & 0.023 & 0.227 & -0.020 & 0.014 & 0.031 & 0.015 & 0.015 & 0.243 & $0.096^{*}$ & 0.022 & $-18.3 \%$ & $-8.6 \%$ \\
\hline$T+4$ & 377 & $95.2 \%$ & 0.504 & $-0.122^{*}$ & 0.024 & 0.226 & -0.020 & 0.015 & 0.031 & 0.022 & 0.015 & 0.240 & $0.120^{*}$ & 0.025 & $-24.2 \%$ & $-8.7 \%$ \\
\hline$T+5$ & 361 & $94.7 \%$ & 0.494 & $-0.126^{\star}$ & 0.023 & 0.228 & -0.017 & 0.016 & 0.032 & $0.031+$ & 0.018 & 0.246 & $0.113^{*}$ & 0.027 & $-25.6 \%$ & $-7.6 \%$ \\
\hline \multicolumn{17}{|l|}{ Men } \\
\hline$T+1$ & 468 & $95.3 \%$ & 0.821 & $-0.076^{*}$ & 0.017 & 0.132 & -0.012 & 0.008 & 0.011 & 0.011 & 0.009 & 0.036 & $0.077^{\star}$ & 0.014 & $-9.3 \%$ & $-8.9 \%$ \\
\hline$T+2$ & 449 & $94.9 \%$ & 0.824 & $-0.103^{*}$ & 0.019 & 0.138 & -0.008 & 0.011 & 0.005 & $0.022^{*}$ & 0.010 & 0.033 & $0.089^{*}$ & 0.016 & $-12.4 \%$ & $-6.0 \%$ \\
\hline$T+3$ & 426 & $94.8 \%$ & 0.822 & $-0.111^{*}$ & 0.020 & 0.141 & -0.007 & 0.011 & 0.002 & $0.034^{*}$ & 0.012 & 0.035 & $0.084^{*}$ & 0.016 & $-13.5 \%$ & $-5.3 \%$ \\
\hline$T+4$ & 407 & $95.1 \%$ & 0.827 & $-0.098^{*}$ & 0.020 & 0.140 & -0.016 & 0.012 & 0.003 & $0.023^{*}$ & 0.011 & 0.031 & $0.091^{*}$ & 0.017 & $-11.9 \%$ & $-11.3 \%$ \\
\hline$T+5$ & 384 & $95.1 \%$ & 0.819 & $-0.097^{\star}$ & 0.021 & 0.148 & -0.015 & 0.013 & 0.003 & $0.020^{*}$ & 0.010 & 0.030 & $0.093^{*}$ & 0.018 & $-11.9 \%$ & $-10.3 \%$ \\
\hline \multicolumn{17}{|c|}{ Education: Primary } \\
\hline$T+1$ & 258 & $94.6 \%$ & 0.602 & $-0.129^{*}$ & 0.027 & 0.127 & 0.003 & 0.013 & 0.020 & 0.013 & 0.014 & 0.250 & $0.114^{*}$ & 0.026 & $-21.5 \%$ & $2.0 \%$ \\
\hline$T+2$ & 249 & $94.4 \%$ & 0.609 & $-0.137^{\star}$ & 0.028 & 0.132 & -0.005 & 0.014 & 0.021 & 0.001 & 0.014 & 0.238 & $0.142^{*}$ & 0.030 & $-22.6 \%$ & $-4.0 \%$ \\
\hline$T+3$ & 241 & $95.0 \%$ & 0.607 & $-0.157^{*}$ & 0.030 & 0.135 & -0.009 & 0.016 & 0.017 & 0.016 & 0.017 & 0.240 & $0.149^{*}$ & 0.031 & $-25.8 \%$ & $-6.4 \%$ \\
\hline$T+4$ & 230 & $94.8 \%$ & 0.619 & $-0.170^{*}$ & 0.032 & 0.142 & -0.006 & 0.019 & 0.018 & 0.019 & 0.019 & 0.220 & $0.157^{*}$ & 0.033 & $-27.5 \%$ & $-4.2 \%$ \\
\hline$T+5$ & 224 & $94.2 \%$ & 0.616 & $-0.162^{*}$ & 0.032 & 0.142 & 0.005 & 0.021 & 0.019 & 0.020 & 0.018 & 0.223 & $0.137^{\star}$ & 0.035 & $-26.2 \%$ & $3.3 \%$ \\
\hline \multicolumn{17}{|c|}{ Education : Secondary } \\
\hline$T+1$ & 398 & $96.5 \%$ & 0.745 & $-0.088^{*}$ & 0.019 & 0.130 & $-0.017 \dagger$ & 0.009 & 0.013 & $0.029^{*}$ & 0.012 & 0.112 & $0.076^{*}$ & 0.016 & $-11.8 \%$ & $-13.1 \%$ \\
\hline$T+2$ & 383 & $96.1 \%$ & 0.747 & $-0.088^{*}$ & 0.021 & 0.133 & -0.014 & 0.011 & 0.008 & $0.028^{*}$ & 0.013 & 0.111 & $0.074^{*}$ & 0.017 & $-11.8 \%$ & $-10.6 \%$ \\
\hline$T+3$ & 362 & $95.6 \%$ & 0.751 & $-0.090^{*}$ & 0.022 & 0.136 & -0.019 & 0.012 & 0.009 & $0.036^{*}$ & 0.014 & 0.104 & $0.072^{*}$ & 0.019 & $-11.9 \%$ & $-13.8 \%$ \\
\hline$T+4$ & 346 & $96.0 \%$ & 0.753 & $-0.083^{*}$ & 0.023 & 0.139 & $-0.026+$ & 0.014 & 0.009 & $0.022+$ & 0.013 & 0.099 & $0.087^{*}$ & 0.020 & $-11.0 \%$ & $-18.8 \%$ \\
\hline$T+5$ & 321 & $95.6 \%$ & 0.743 & $-0.078^{*}$ & 0.024 & 0.147 & $-0.029+$ & 0.016 & 0.010 & $0.022+$ & 0.013 & 0.101 & $0.084^{*}$ & 0.022 & $-10.4 \%$ & $-19.6 \%$ \\
\hline \multicolumn{17}{|c|}{ Education : Above A level } \\
\hline$T+1$ & 264 & $94.3 \%$ & 0.590 & $-0.045^{\star}$ & 0.020 & 0.297 & $-0.015+$ & 0.009 & 0.028 & 0.002 & 0.012 & 0.084 & $0.059^{*}$ & 0.017 & $-7.6 \%$ & $-5.2 \%$ \\
\hline$T+2$ & 245 & $94.7 \%$ & 0.591 & $-0.067^{*}$ & 0.025 & 0.306 & -0.009 & 0.015 & 0.026 & 0.009 & 0.015 & 0.078 & $0.067^{*}$ & 0.022 & $-11.3 \%$ & $-2.8 \%$ \\
\hline$T+3$ & 229 & $94.3 \%$ & 0.583 & $-0.061^{*}$ & 0.027 & 0.310 & -0.010 & 0.017 & 0.028 & 0.015 & 0.017 & 0.079 & $0.056^{*}$ & 0.022 & $-10.5 \%$ & $-3.1 \%$ \\
\hline$T+4$ & 208 & $94.2 \%$ & 0.592 & $-0.089^{*}$ & 0.031 & 0.296 & -0.016 & 0.017 & 0.026 & 0.029 & 0.019 & 0.087 & $0.076^{*}$ & 0.027 & $-15.0 \%$ & $-5.5 \%$ \\
\hline $\mathrm{T}+5$ & 200 & $94.5 \%$ & 0.582 & $-0.109^{*}$ & 0.031 & 0.302 & -0.020 & 0.019 & 0.026 & $0.036+$ & 0.021 & 0.090 & $0.093^{*}$ & 0.030 & $-18.7 \%$ & $-6.5 \%$ \\
\hline
\end{tabular}


Table 7: Effect of a disability on labour market status according to the median age

\begin{tabular}{|c|c|c|c|c|c|c|c|c|c|c|c|c|c|c|c|c|}
\hline \multirow{2}{*}{ Health event time } & \multirow{2}{*}{ Treated } & \multirow{2}{*}{ Matched } & \multicolumn{3}{|c|}{ Employment in the private sector } & \multicolumn{3}{|c|}{ Employment in the public sector } & \multicolumn{3}{|c|}{ Unemployment } & \multicolumn{3}{|c|}{ Inactivity } & \multirow{2}{*}{$\begin{array}{c}\text { Private } \\
\text { sector } \\
\text { relative ATT } \\
(2) /(1)\end{array}$} & \multirow{2}{*}{$\begin{array}{c}\text { Public sector } \\
\text { relative ATT } \\
\text { (4)/(3) }\end{array}$} \\
\hline & & & YO (1) & ATT (2) & ASE & YO (3) & ATT (4) & ASE & Yo & ATT & ASE & Yo & ATT & ASE & & \\
\hline \multicolumn{17}{|c|}{ Age at disability< 36} \\
\hline$T+1$ & 425 & $95.8 \%$ & 0.725 & $-0.059^{*}$ & 0.017 & 0.150 & -0.008 & 0.009 & 0.027 & 0.004 & 0.011 & 0.098 & $0.064^{*}$ & 0.015 & $-8.2 \%$ & $-5.7 \%$ \\
\hline$T+2$ & 411 & $96.1 \%$ & 0.727 & $-0.056^{*}$ & 0.020 & 0.149 & 0.001 & 0.011 & 0.023 & -0.003 & 0.011 & 0.101 & $0.059^{*}$ & 0.018 & $-7.8 \%$ & $0.4 \%$ \\
\hline$T+3$ & 400 & $96.3 \%$ & 0.719 & $-0.052^{*}$ & 0.021 & 0.153 & 0.000 & 0.013 & 0.023 & 0.007 & 0.013 & 0.104 & $0.044^{*}$ & 0.017 & $-7.2 \%$ & $0.3 \%$ \\
\hline$T+4$ & 379 & $96.6 \%$ & 0.719 & $-0.061^{*}$ & 0.022 & 0.150 & -0.004 & 0.014 & 0.025 & 0.007 & 0.014 & 0.107 & $0.057^{*}$ & 0.019 & $-8.4 \%$ & $-2.4 \%$ \\
\hline$T+5$ & 364 & $96.4 \%$ & 0.712 & $-0.063^{*}$ & 0.022 & 0.154 & -0.003 & 0.015 & 0.026 & 0.005 & 0.013 & 0.108 & $0.061^{*}$ & 0.020 & $-8.8 \%$ & $-1.8 \%$ \\
\hline \multicolumn{17}{|c|}{ Age at disability $>=36$} \\
\hline$T+1$ & 495 & $94.9 \%$ & 0.606 & $-0.112^{*}$ & 0.018 & 0.200 & $-0.014+$ & 0.008 & 0.013 & $0.028^{*}$ & 0.010 & 0.181 & $0.098^{*}$ & 0.016 & $-18.5 \%$ & $-6.8 \%$ \\
\hline$T+2$ & 466 & $94.6 \%$ & 0.608 & $-0.129^{*}$ & 0.019 & 0.209 & $-0.020^{*}$ & 0.010 & 0.014 & $0.029^{*}$ & 0.012 & 0.170 & $0.120^{*}$ & 0.018 & $-21.2 \%$ & $-9.7 \%$ \\
\hline$T+3$ & 432 & $94.7 \%$ & 0.611 & $-0.146^{*}$ & 0.022 & 0.210 & $-0.026^{*}$ & 0.012 & 0.012 & $0.039^{\star}$ & 0.014 & 0.166 & $0.133^{*}$ & 0.021 & $-23.8 \%$ & $-12.4 \%$ \\
\hline$T+4$ & 405 & $94.6 \%$ & 0.627 & $-0.154^{*}$ & 0.022 & 0.209 & $-0.031^{*}$ & 0.012 & 0.010 & $0.035^{\star}$ & 0.013 & 0.154 & $0.150^{*}$ & 0.022 & $-24.6 \%$ & $-14.7 \%$ \\
\hline$T+5$ & 381 & $94.2 \%$ & 0.613 & $-0.156^{*}$ & 0.022 & 0.217 & $-0.028^{*}$ & 0.014 & 0.011 & $0.042^{*}$ & 0.014 & 0.159 & $0.143^{*}$ & 0.023 & $-25.5 \%$ & $-13.1 \%$ \\
\hline
\end{tabular}

Note: * : significant at the $5 \%$ level. + : significant at the $10 \%$ level. Y0 : average value of the performance variable among the treated one year before the treatment. ATT : Average effect of the Treatment on the Treated. ASE : Asymptotic Standard Error. The $95 \%$ confidence interval is defined as ATT \pm 1.96 ASE. 
Table 8: Effect of a disability on labour market status according the median age by gender

\begin{tabular}{|c|c|c|c|c|c|c|c|c|c|c|c|c|c|c|c|c|}
\hline \multirow{2}{*}{ Health event time } & \multirow{2}{*}{ Treated } & \multirow{2}{*}{ Matched } & \multicolumn{3}{|c|}{$\begin{array}{c}\text { Employment in the private } \\
\text { sector }\end{array}$} & \multicolumn{3}{|c|}{ Employment in the public sector } & \multicolumn{3}{|c|}{ Unemployment } & \multicolumn{3}{|c|}{ Inactivity } & \multirow{2}{*}{$\begin{array}{l}\text { Private } \\
\text { sector } \\
\text { relative ATT } \\
\text { (2)/(1) }\end{array}$} & \multirow{2}{*}{$\begin{array}{c}\text { Public } \\
\text { sector } \\
\text { relative AT } \\
(4) /(3)\end{array}$} \\
\hline & & & Y0 (1) & ATT (2) & ASE & Yo (3) & ATT (4) & ASE & Y0 & ATT & ASE & Yo & ATT & ASE & & \\
\hline \multicolumn{17}{|c|}{ Women: Age at disability $<39$} \\
\hline$T+1$ & 206 & $96.1 \%$ & 0.540 & $-0.072^{*}$ & 0.027 & 0.227 & -0.013 & 0.012 & 0.035 & 0.009 & 0.019 & 0.197 & $0.076^{*}$ & 0.025 & $-13.3 \%$ & $-5.8 \%$ \\
\hline$T+2$ & 201 & $96.5 \%$ & 0.541 & -0.044 & 0.030 & 0.222 & -0.007 & 0.015 & 0.036 & -0.016 & 0.018 & 0.201 & $0.067^{\star}$ & 0.029 & $-8.2 \%$ & $-3.0 \%$ \\
\hline$T+3$ & 199 & $96.5 \%$ & 0.536 & -0.026 & 0.031 & 0.224 & 0.003 & 0.018 & 0.036 & -0.012 & 0.018 & 0.203 & 0.035 & 0.029 & $-4.9 \%$ & $1.5 \%$ \\
\hline$T+4$ & 189 & $96.3 \%$ & 0.544 & $-0.068^{*}$ & 0.033 & 0.209 & 0.003 & 0.021 & 0.038 & 0.008 & 0.023 & 0.209 & $0.057 \dagger$ & 0.033 & $-12.6 \%$ & $1.6 \%$ \\
\hline$T+5$ & 181 & $95.6 \%$ & 0.532 & $-0.075^{*}$ & 0.035 & 0.214 & 0.003 & 0.022 & 0.040 & 0.016 & 0.024 & 0.214 & 0.056 & 0.036 & $-14.2 \%$ & $1.6 \%$ \\
\hline \multicolumn{17}{|c|}{ Men: Age at disability $<33$} \\
\hline$T+1$ & 211 & $94.8 \%$ & 0.860 & $-0.057^{*}$ & 0.023 & 0.100 & -0.005 & 0.014 & 0.010 & 0.009 & 0.012 & 0.030 & $0.052^{*}$ & 0.019 & $-6.6 \%$ & $-4.7 \%$ \\
\hline$T+2$ & 203 & $95.1 \%$ & 0.860 & $-0.076^{*}$ & 0.026 & 0.104 & 0.009 & 0.017 & 0.005 & 0.022 & 0.015 & 0.031 & $0.046^{*}$ & 0.018 & $-8.9 \%$ & $8.6 \%$ \\
\hline$T+3$ & 196 & $95.4 \%$ & 0.856 & $-0.078^{*}$ & 0.028 & 0.107 & 0.006 & 0.018 & 0.005 & $0.032^{*}$ & 0.015 & 0.032 & $0.041^{*}$ & 0.018 & $-9.1 \%$ & $5.2 \%$ \\
\hline$T+4$ & 186 & $95.7 \%$ & 0.854 & $-0.059^{*}$ & 0.028 & 0.107 & -0.004 & 0.020 & 0.006 & 0.018 & 0.014 & 0.034 & $0.045^{*}$ & 0.018 & $-6.9 \%$ & $-3.5 \%$ \\
\hline$T+5$ & 179 & $96.1 \%$ & 0.849 & $-0.053+$ & 0.030 & 0.110 & -0.001 & 0.023 & 0.006 & 0.006 & 0.012 & 0.035 & $0.049^{*}$ & 0.018 & $-6.3 \%$ & $-1.1 \%$ \\
\hline \multicolumn{17}{|c|}{ Women: Age at disability $>=39$} \\
\hline$T+1$ & 246 & $94.7 \%$ & 0.459 & $-0.123^{*}$ & 0.025 & 0.219 & -0.008 & 0.012 & 0.021 & $0.034^{*}$ & 0.016 & 0.300 & $0.097^{*}$ & 0.023 & $-26.8 \%$ & $-3.8 \%$ \\
\hline$T+2$ & 227 & $94.3 \%$ & 0.458 & $-0.131^{*}$ & 0.027 & 0.229 & -0.018 & 0.016 & 0.023 & 0.030 & 0.019 & 0.290 & $0.119^{*}$ & 0.027 & $-28.6 \%$ & $-7.8 \%$ \\
\hline$T+3$ & 207 & $94.7 \%$ & 0.464 & $-0.155^{\star}$ & 0.032 & 0.230 & $-0.042^{*}$ & 0.020 & 0.026 & $0.041+$ & 0.022 & 0.281 & $0.157^{*}$ & 0.032 & $-33.4 \%$ & $-18.4 \%$ \\
\hline$T+4$ & 188 & $94.7 \%$ & 0.466 & $-0.178^{*}$ & 0.031 & 0.242 & $-0.043+$ & 0.022 & 0.022 & $0.036+$ & 0.020 & 0.270 & $0.185^{\star}$ & 0.033 & $-38.1 \%$ & $-17.8 \%$ \\
\hline$T+5$ & 180 & $94.4 \%$ & 0.459 & $-0.177^{*}$ & 0.033 & 0.241 & -0.038 & 0.024 & 0.024 & $0.046^{*}$ & 0.023 & 0.276 & $0.169^{*}$ & 0.037 & $-38.6 \%$ & $-15.9 \%$ \\
\hline \multicolumn{17}{|c|}{ Men: Age at disability >=33 } \\
\hline$T+1$ & 257 & $95.7 \%$ & 0.789 & $-0.092^{*}$ & 0.023 & 0.159 & -0.017 & 0.011 & 0.012 & 0.012 & 0.013 & 0.041 & $0.098^{*}$ & 0.021 & $-11.7 \%$ & $-10.9 \%$ \\
\hline$T+2$ & 246 & $95.1 \%$ & 0.795 & $-0.124^{*}$ & 0.026 & 0.167 & $-0.023+$ & 0.012 & 0.004 & 0.022 & 0.014 & 0.034 & $0.124^{*}$ & 0.025 & $-15.6 \%$ & $-13.7 \%$ \\
\hline$T+3$ & 230 & $94.8 \%$ & 0.794 & $-0.139^{\star}$ & 0.029 & 0.170 & -0.018 & 0.012 & 0.000 & $0.037^{\star}$ & 0.017 & 0.037 & $0.121^{*}$ & 0.026 & $-17.6 \%$ & $-10.9 \%$ \\
\hline$T+4$ & 221 & $95.0 \%$ & 0.805 & $-0.131^{*}$ & 0.029 & 0.167 & $-0.026^{*}$ & 0.012 & 0.000 & $0.028+$ & 0.015 & 0.029 & $0.128^{*}$ & 0.028 & $-16.3 \%$ & $-15.4 \%$ \\
\hline$T+5$ & 205 & $94.6 \%$ & 0.794 & $-0.137^{\star}$ & 0.030 & 0.180 & $-0.026+$ & 0.015 & 0.000 & $0.031+$ & 0.016 & 0.026 & $0.133^{*}$ & 0.030 & $-17.3 \%$ & $-14.6 \%$ \\
\hline
\end{tabular}

Treated. ASE : Asymptotic Standard Error. The $95 \%$ confidence interval is defined as ATT \pm 1.96 ASE. 
14_16. Employer-provided health insurance and equilibrium wages with two-sided heterogeneity

Arnaud Chéron, Pierre-Jean Messe, Jérôme Ronchetti

14_15. Does subsiding young people to learn to drive promote social inclusion? Evidence from a large controlled experiment in France

Julie Le Gallo, Yannick L'Horty, Pascale Petit

14_14. Hiring discrimination based on national origin and the competition between employed and unemployed job seekers

Guillaume Pierné

14_13. Discrimination in hiring: The curse of motorcycle women

Loïc Du Parquet, Emmanuel Duguet, Yannick L'Horty, Pascale Petit

14_12. Residential discrimination and the ethnic origin: An experimental assessment in the Paris suburbs

Emmanuel Duguet, Yannick L'Horty, Pascale Petit

14_11. Discrimination based on place of residence and access to employment

Mathieu Bunel, Yannick L'Horty, Pascale Petit

14_10. Rural Electrification and Household Labor Supply: Evidence from Nigeria Claire Salmon, Jeremy Tanguy

14_9. Effects of immigration in frictional labor markets: theory and empirical evidence from EU countries

Eva Moreno-Galbis, Ahmed Tritah

14_8. Health, Work and Working Conditions: A Review of the European Economic Literature

Thomas Barnay

14_7. Labour mobility and the informal sector in Algeria: a cross-sectional comparison (2007-2012)

Philippe Adair, Youghourta Bellache

14_6. Does care to dependent elderly people living at home increase their mental health? Thomas Barnay, Sandrine Juin

14_5. The Effect of Non-Work Related Health Events on Career Outcomes: An Evaluation in the French Labor Market

Emmanuel Duguet, Christine le Clainche

14_4. Retirement intentions in the presence of technological change: Theory and evidence from France

Pierre-Jean Messe, Eva Moreno - Galbis, Francois-Charles Wolff

14_3. Why is Old Workers' Labor Market more Volatile? Unemployment Fluctuations over the Life-Cycle 
Jean-Olivier Hairault, François Langot, Thepthida Sopraseuth

14_2. Participation, Recruitment Selection, and the Minimum Wage Frédéric Gavrel

14_1. Disparities in taking sick leave between sectors of activity in France: a longitudinal analysis of administrative data

Thomas Barnay, Sandrine Juin, Renaud Legal 
The CNRS Institute for Labor Studies and Public Policies (the TEPP Institute, FR $n^{\circ} 3435$ CNRS) gathers together research centres specializing in economics and sociology:

- l'Equipe de Recherche sur les Marchés, l'Emploi et la Simulation (Research Team on Markets, Employment and Simulation), ERMES, University of Paris II PanthéonAssas

- the Centre d'Etudes des Politiques Economiques de l'université d'Evry (Research Centre focused on the analysis of economic policy and its foundations and implications), EPEE, University of Evry Val d'Essonne

- the Centre Pierre Naville (Research on Work and Urban Policies), CPN, University of Evry Val d'Essonne

- l'Equipe de Recherche sur l'Utilisation des Données Temporelles en Economie (Research Team on Use of Time Data in Economics), ERUDITE, University of ParisEst Créteil and University of Paris-Est Marne-la-Vallée

- the Groupe d'Analyse des Itinéraires et des Niveaux Salariaux (The Group on Analysis of Wage Levels and Trajectories), GAINS, University of the Maine

The TEPP Institute brings together 147 researchers and research professors and $100 \mathrm{PhD}$ students who study changes in work and employment in relation to the choices made by firms and analyse public policies using new evaluation methods. 